\title{
Colonialismo, marginación y permanencia del huauhtli en Morelos y Puebla, México
}

\author{
Colonialism, marginalization and permanence of the huauhtli in Morelos \\ and Puebla, Mexico
}

\section{Colonialismo, marginalização e permanência do huauhtli em Morelos e Puebla, México}

\section{Rodrigo Meiners Mandujano ${ }^{1}$}

Instituto de Estudios Brasileños de la Universidad de São Paulo

\author{
rodrigomeiners@usp.br \\ Código ORCID: https://orcid.org/0000-0002-1876-1137
}

\begin{abstract}
RESUMEN
El huauhtli fue domesticado por los pueblos originarios del centro de México, y entre 1500 y 900 a.C. ya estaba generalizado su cultivo entre los habitantes de la región. Esta planta es comprendida como patrimonio histórico alimentario en localidades campesinas del oriente de Morelos, en Huazulco y Amilcingo, municipio de Temoac, en la región de la barranca del Amatzinac; y también, en los pueblos en las laderas al sur del volcán Popocatépetl, pertenecientes al municipio de Tochimilco y Atzitzihuacán. Los pueblos de Morelos, además de cultivar el huauhtli, son especializados en la elaboración de productos a base de amaranto. En los pueblos del volcán esta planta se cultiva de forma muy antigua, y hoy son los principales productores a nivel nacional. Estos pueblos protegieron las variedades de huauhtli, incluso en condiciones desastrosas, como la pérdida del agua de riego, a través del uso de la memoria ancestral, agricultura, religiosidad e identidad, que se observada en las fiestas y ferias calendáricas. Desde el 2008, se realiza trabajo de campo en la región, se han efectuado visitas, recorridos, participación en eventos comunitarios y gubernamentales, y entrevistas semiestructuradas con los campesinos, miembros de los talleres, autoridades y organizaciones. Se muestra la permanencia de los usos del huauhtli como principal actividad económica, tanto en la elaboración de productos en Morelos, como en la venta de las semillas en Puebla. El amaranto permaneció en estas poblaciones con vínculos comunitarios, resistiendo el colonialismo alimentario, el desprecio colonial, el olvido republicano y la insolencia capitalista.
\end{abstract}

\begin{abstract}
The huauhtli was domesticated by the native peoples of central Mexico, and between 1500 and 900 B.C., its cultivation was already widespread among the people of the region. This plant is included as a historical food heritage in rural localities in eastern Morelos, in Huazulco and Amilcingo, municipality of Temoac, in the Amatzinac Ravine (Barranca del Amatzinac) region; and also, in the small cities on the slopes south of the Popocatépetl volcano, belonging to the municipality of Tochimilco and Atzitzihuacán. The pueblos of Morelos, in addition to cultivating the huauhtli, are specialized in the elaboration of products based on amaranth. In the communities of the volcano this plant is cultivated since ancient times, and today they are the main producers nationwide. These peoples protected the varieties of huauhtli, even in disastrous conditions, such as the loss of irrigation water, through the use of ancestral memory, agriculture, religiosity and identity, which is observed in the calendrical religious
\end{abstract}

1 Posdoctorante del Instituto de Estudios Brasileños de la Universidad de São Paulo (IEB-USP). Esta investigación contó con una beca doctoral (2013-2017), financiada por el Consejo Nacional de Ciencia y Tecnología- CONACYT, de México. geografías y ciencias sociales, 2(3), 035 - 056. http://dx.doi.org/10.15381/espiral.v2i3.18448 
times. Since 2008, field work has been carried out in the region, mainly visits, tours, participation in community and government events, and semi-structured interviews with farmers, workshop members, authorities and organizations. The permanence of the uses of huauhtli as the main economic activity is shown, both in the elaboration of products in Morelos and in the sale of seeds in Puebla. Amaranth remained in these populations with community ties, resisting food colonialism, colonial contempt, republican oblivion and capitalist insolence.

\section{RESUMO}

O huauhtli foi domesticado pelos povos originarios do centro do México, e entre 1500 y 900 a.C. já estava generalizado o seu cultivo entre os habitantes da região. Esta planta é comprendida como patrimônio histórico alimentaria em localidades camponesas do oriente de Morelos, em Huazulco e Amilcingo, município de Temoac, na região da "Barranca del Amatzinac"; e também, nos povos das ladeiras ao sul do vulcão Popocatépetl, pertencentes ao município de Tochimilco e Atzitzihuacán. As localidades de Morelos, ademais de cultivar o huauhtli, são especializados na elaboração de produtos à base de amaranto. Nas comunidades do volcão, esta planta se cultiva de forma muito antiga, e hoje são os principais produtores a nível nacional. Estes pueblos protegieram as variedades de huauhtli, incluso em condições desastrosas, como a perda da agua de irrigação, a través do uso da memória ancestral, agricultura, religiosidade e identidade, que se observam nas festas e feiras do calendário religioso. Desde o ano 2008, se realiza trabalho de campo na região, visitas foram feitas, recorridos, participação em eventos comunitários e governamentais, e entrevistas semi-estruturadas com os camponeses, membros das fábricas pequenas, autoridades e organizações. Se muestra a permanencia dos usos do huauhtli como principal atividade económica, tanto em a elaboração de produtos em Morelos, como na venta das sementes em Puebla. O amaranto permaneció en estas populações com vínculos comunitários, resistindo o colonialismo alimentar, o desprecio colonial, o esquecimento republicano e a insolência capitalista.

PALABRAS CLAVE: huauhtli; amaranto; alegría; pueblos originarios; campesinos; colonialismo.

KEYWORDS: huauhtli; alegría; amaranth; Indigenous People; peasant; colonialism.

PALAVRAS-CHAVE: huauhtli; amaranto; alegría; povos originários; camponeses; colonialismo.

\section{Huauhtli: de cuerpo de los dioses a alimento profano. Sincretismo religioso- alimentario en México}

El huauhtli, alegría o amaranto (Amaranthus hypocondriacus, Amaranthus cruentus) fue domesticado para obtener la semilla y verdura por los pueblos originarios del centro de México, y entre 1500 y 900 a.C. ya estaba generalizado su cultivo en lo que hoy se define como milpa, en conjunto con el maíz, frijol, chile, calabaza, zapote y algodón, alimentos sembrados en las parcelas, desde por lo menos 10 mil años, hasta el día de hoy. Los datos arqueológicos, etnográficos, paleográficos, cartográficos, archivísticos e históricos, muestran la presencia de estas plantas en grande escala en las sociedades originarias de México. El amaranto también fue domesticado en las tierras andinas (llamadas de kiwicha) desde las culturas preincas y quechuas (Amaranthus caudatus), acompañando sus primas-hermanas quinuas (Chenopodium quinoa). Al respecto de la no domesticación de estas plantas tendría que ser probada.

En México, las plantas cultivadas para obtención de semillas (Amaranthushypocondriacus y Amaranthus cruentus) son llamadas en español de "alegría" o amaranto (que significa inmortal del griego amaranthus) y en el idioma náhuatl huauhtli, sin traducción aparente.

En Amilcingo y Huazulco, Morelos, se acostumbra sembrar desde tiempos prehispánicos la variedad criollo-amilcingo (Amaranthus cruenthus var. criolloamilcingo o dorada-amilcingo), pero también la especie Amaranthus hypocondriacus (payasita), y en los municipios de Tochimilco y Atzitzihuacán, Puebla, es más común la siembra de la Amaranthus hypocondriacus.

Las hojas y tallos del género Amaranthus spp., son comestibles, por ejemplo, los llamados quilitl, quelitl o huauhquilitl (Amaranthus hybridus, entre otras especies), hasta 
su castellanización en el caso de México para quelite, que significa del náhuatl "yerva que se come como bledos \&[etcetera]", conforme el diccionario anónimo "Dictionnaire espagnol nahuatl (17??, s/p apud UNAM, Acceso 4 de septiembre del 2018). Existen centenas de especies y variedades distribuidas en los cinco continentes, llamadas en España de bledos y en Portugal de bredos (Amaranthus blitum) (proveniente del griego bliton, que derivó blitum en latin, que significa insípido o sin importancia), refiriéndose como verdura y no a la semilla.

Para entender la variedad de plantas comestibles de la familia amaranthaceae, puede mencionarse la subfamilia chenopoidea, como los epazotes o cenizos (género Chenopodium álbum), huauhzontle o huauzontle (Chenopodium natulliae), las quinuas o quinoas (Chenopodium quinua), cañihuas o kañiwas (Chenopodium palidicaulle), pero también la espinaca (Spinace oleraceae), que fue traída de Europa.

El tzoalli, tzoale o zoale, es un tipo de tamal de masa de las semillas del amaranto, el cual es importante reflexionar como base de la cultura alimentaria en la época prehispánica, por ser parte del calendario ritual mexica y de otros grupos de pueblos originales. El tzoali es un alimento que, realmente, fue alejado de la cotidianidad alimentaria de México durante la época colonial, por medio de una presión intensa ejercida por el poder colonial y sus instituciones religiosas. Además del maíz que sustenta al pueblo, la adhesión imperante del trigo, como base alimentaria europea desde los inicios de la Nueva España, representan, en conjunto con los productos de ultramar, como el café, la caña-de-azúcar, etc., la base alimentaria del pueblo mexicano, que acompaña la dieta prehispánica. El huauhtli, el huauhzontle y la chía, destacan por haber sido mantenidas muy al margen de lo que un día significaron para los pueblos.

Pero, a grandes rasgos, en Centro y Norteamérica la semilla era usada de muchas maneras además de las figuras rituales en el calendario religioso, pues, sus semillas fueron y son reventadas y tostadas al calor en una superficie de barro (comal); hervidas y consumidas en sopas y guisados cuando los brotes de las plantas están tiernos; el uso de harina en tortillas, atoles (considerados bebidas para purificación y ayunos), en tamales; harina mezcladas con miel de abejas nativas o de agave (aguamiel sin fermentar); adicionado al pulque (bebida fermentada de aguamiel extraída del agave pulquero); los quelites para relleno en los tamales o al fuego en la cazuela con aceite o grasa animal, caldos condimentados con chiles (ajís), guisos con otras plantas y frutos, carnes de aves o pescados; y en emplastos medicinales. Una de las fuentes más conocidas, sobre la gastronomía prehispánica, es el códice Florentino, libros X a XII (1577), así como, las relaciones de los ocupantes españoles, desde Hernán Cortés a los frailes dominicos, agustinos y franciscanos, que comenzaron el "arduo esfuerzo" de evangelización de los pueblos. Estas menciones hacen todo sentido a la realidad de la gastronomía tradicional mexicana como patrimonio mundial de la humanidad, reconocida por la UNESCO desde el año 2010.

En gran parte de lo que hoy es México era muy importante la confección de ídolos prehispánicos con la masa obtenida de las semillas de amaranto, llamada de zoali, tzoali o tzoalli, la cual está documentada ampliamente en los textos coloniales a partir de la primera década del siglo XVI. Esto, por ser parte de la materia prima fundamental, haciendo uso de la masa para la confección ritual de la deidad mexica Huitzilopochtli, pero también de los otros Dioses y Diosas mexicas (y otras culturas como la maya o wixárika). Así como, representaciones de figuras geomorfológicas, como el volcán Popocatépetl y las más diversas siluetas zoomórficas finamente ataviadas. Las más importantes ceremonias incluían estos ídolos en gran parte de las celebraciones del imperio mexica, muy documentadas en los códices y los relatos de los religiosos y conquistadores españoles. 
Ahí la principal explicación de la marginación y persecución a los agricultores. Resaltan también los relatos de frailes españoles, sobretodo, Toribio de Benevante (Motolinia), Joseph de Acosta, Diego Durán, Martín de Valencia, Bernardino de Sahagún y Juan de Córdova. Todos ellos confirman tales informaciones durante el siglo XVI. A través de otros padres más conservadores aún, ya nacidos en México, como Jacinto de la Serna ([1656] 1892, p. 267), que, a más de un siglo de la llegada de los primeros frailes, destaca la permanencia de las prácticas rituales con masas de amaranto en su obra "El Manual de Ministros para el conocimiento de sus idolatrías y extirpación de ellas". Este religioso llama la atención ante la semejanza e "injurias profanas" de las fiestas de los antiguos junto con las cristianas y su calendario. En dicho manual, se lee una de las principales causas de su necesaria extirpación, por un "un cierto genero de médicos, que ellos tienen entre sí que los turban de manera, que no los dexan desarraigarse de sus supersticiones, y reliquias de su idolatría".

Una de las estrategias que concierne al huauhtli, para alegar a los pueblos de sus "profanas costumbres", fue la confección y la creación de las llamadas barras de alegría en los primeros conventos españoles de los franciscanos, como Fray Martin de Valencia (1474-1534), líder de los doce apóstoles², llegados a México en 1524, y con la continua llegada de jesuitas y dominicanos españoles en las décadas posteriores en Puebla, Estado de México y Morelos. Los conventos fueron instalados en las faldas de los volcanes Popocatépetl e Iztaccíhuatl, pero también en los pueblos la barranca, ya mencionada. Esos conventos fueron los primeros construidos en la Nueva España, hoy reconocidos como patrimonio cultural de la humanidad desde el año desde el año de 1994.

Las barras de alegría son una preparación dulce a base de semillas de amaranto aglutinadas con miel y panela, pasado del punto de calor en una hoya de cobre, y, finalmente, cortadas en forma de barras antes de enfriar la mezcla aglutinada con las semillas, hasta que se recristalizan los azúcares y queda lista para su consumo. Hasta el día de hoy son las formas más populares de consumo en el país, junto con las obleas, que es una especie de ostia sacramental de mayor tamaño, ambas fabricadas en los pueblos de Huazulco y Amilcingo.

La barra de alegría con miel y piloncillo (panela) era fabricada en Europa, Asia y norte de África, con la semilla de ajonjolí (Sesamum indicum L.). Los primeros frailes en la región, desde 1524, y por las monjas que fundaron su primer convento en la Ciudad de México en 1530, impusieron esta manera de preparar el huauhtli. De hecho, el nombre alegría que se usa para el huauhtli en México, originalmente es la designación dada a la planta de ajonjolí (Sesamum indicum) (también llamada sésamo), hasta el siglo XIV y XV en España. Y llamaban de esta forma tanto a la planta y sus semillas como al dulce, transferido y sustituyendo al nombre huauhtli, probablemente por la analogía en el cierto parecido de la semilla y la capacidad para preparar las barras con el mismo método asiático-europeo ${ }^{3}$.

Las obleas preparadas con mezcla de harina de amaranto y trigo, así como los dulces llamados de alegrías de amaranto resultaron de las preparaciones que permanecerían en la sociedad mexicana, principalmente durante la Semana Santa en el martes santo de Huazulco, el Día de Muertos y la virgen de Santa Catarina Huazulco en el mes de noviembre, y, finalmente, las fiestas a la Virgen de Guadalupe del Tepeyac cada 12 de diciembre.

La chía y los dulces eran comunes en las fiestas religiosas hasta finales del siglo XVIII, dada la prohibición de su venta por la publicación de mandatos llamados "Bandos", que la población tendría que cumplir rigurosamente durante las procesiones que se realizaban en las festividades de Semana Santa, prohibiendo la instalación de puestos

2 Toribio de Benevante o Motolinia era uno más de ellos.

3 El ajonjolí también fue introducido por los españoles y es un cultivo campesino común en México. 
de "almuerzos dulces y puestos de chías y cosas semejantes en las calles". Esos documentos fueron redactados por el virrey Revillagigedo en 1790 y 1791, llamando al "desorden" de viejas costumbres, como justifica un segundo Bando virreinal, prohibiendo la venta de los dulces de alegría y aguas de chías, que, según el propio virrey Revillagigedo, en el Bando publicado el 23 de marzo de 1790, se implementaría "con la justa mira de corregir el desorden con que muchos individuos de ambos sexos concurren a procesiones de semana santa, convirtiendo en regocijo, destemplanza y desacato la seriedad de unos días que ofrecen ciertamente a la memoria de los piadosos recuerdos".

Pero, la chía y el amaranto continúan, hasta el día de hoy, en los puestos de aguas frescas y tablados de dulces en estas mismas celebraciones, $y$, hasta hace poco, antes del fenómeno comercial "quinua boom, amaranto boom y chía boom, eran la única forma de consumo en el país, tanto en lugares públicos como venta urbana en pequeña escala en puestos ambulantes.

Pero, es Sor Juana Inés de la Cruz ([1689] 1994), quien ejemplifica el proceso de colonización y religiosidad en disputa, En su Auto sacramental de "El Divino Narciso" y la Loa para el auto sacramental de El divino Narciso (por alegorías), con clara alusión y detalle a las costumbres relacionadas a Huitzilopochtli, el "Dios de las semillas" del pueblo mexicano. Esto lo hace de una forma más reflexiva y crítica, con destino a representarse en la Corte de Madrid a pedido de la Condesa de Paredes, virreina de la Nueva España (1680-1686), esta obra se representaría comúnmente en México, en espacios teatrales y conventos. Las obras de la literata fueron resultado del estudio de los textos de los frailes, y su propia vivencia desde joven con la población indígena, con la cual aprendió el náhuatl, por ejemplo, en la Hacienda Panoyan, en Amecameca, en el actual estado de México o en Nepantla de Sor Juana Inés de la Cruz, en la frontera de lo que hoy es el estado de México y Morelos, ambas localidades, ubicadas en las faldas de la región de los volcanes.

A partir de lo expuesto, es posible afirmar que el huauhtli puede ser concebido como patrimonio histórico alimentario en localidades campesinas de México, como los pueblos originarios de la región de la Barranca del Amatzinac y de las laderas del volcán Popocatéptl, en los estados de Morelos y Puebla, respectivamente, que cultivan el amaranto desde tiempos milenarios. En esta región, los pueblos se organizan en torno al cultivo y procesamiento del amaranto, constituyéndose como una de las principales regiones productivas especializadas en la elaboración de los productos a base de amaranto. Esta particularidad permite investigar cómo se establecen las relaciones sociales en torno a un alimento como el huauhtli, en donde el presente trabajo analiza cómo se conforman estas relaciones, que abarcan desde las de ámbito productivo, como la producción y procesamiento del amaranto, hasta las comunitarias, en lo que respecta al cultivo, las festividades y ferias.

El huauhtli es una planta destacada que se distingue nutricionalmente en el mundo, por ejemplo, por su presencia de todos los aminoácidos esenciales, ser libre de gluten, alto contenido de fibra, proteína y vitaminas, abundancia de elementos esenciales, como el calcio, fierro, magnesio, su acción antioxidante, entre otras características benéficas que no se abundarán aquí. Estas plantas se consumen aún tiernas y sin las flores, además, de que en el caso de las hojas y talles tiernos deben cocinarse por 15 minutos al fuego para deshacerse de posibles sustancias no digeribles por el cuerpo humano.

\section{El huauhtli en la Barranca del Amatzinac y las laderas del Popocatéptl}

Se propone que desde lo local y regional acontecen procesos notables que no son nacientes de la lógica colonial occidental. Estas comunidades condensan viejas prácticas que nada tienen que ver con la visión euro-centrista y modernizadora, entrando así 
en conflicto y disputa, una y otra vez, sea por visiones de desarrollo contrapuestas en relación a la agricultura, o la imposición de proyectos de infraestructura que traslapan los modos de organizarse y de vivir.

El trabajo de campo se ha llevado a cabo en la región desde el año 2008, que comprende el inicio de territorios interconectados por viejos caminos prehispánicos, entre barrancas, parcelas, valles y vegetación nativa, sobre las laderas del volcán Popocatépetl, en la dirección que siguen las aguas que descienden hacia el suroeste del volcán, pasando por las pendientes templadas y tierras fértiles de origen volcánico, en los municipios de Tochimilco y Atzizihuacán, en el estado de Puebla, hasta llegar al suroeste en los pueblos de la barraca del oriente de Morelos, más específicamente, Huazulco y Amilcingo, en el municipio de Temoac.

En los días actuales, los campesinos de los pueblos que se encuentran en la ladera sur del volcán, como San Francisco Huilango, Tochimilco e San Juan Amecac, del estado de Puebla, son los que más cultivan el huauhtli en el país. En conjunto con la región oriental de Tlaxcala, estos pueblos abastecen la carencia de semillas para los talleres y fábricas familiares de los productos a base de amaranto en Morelos. (Figura 1-2)

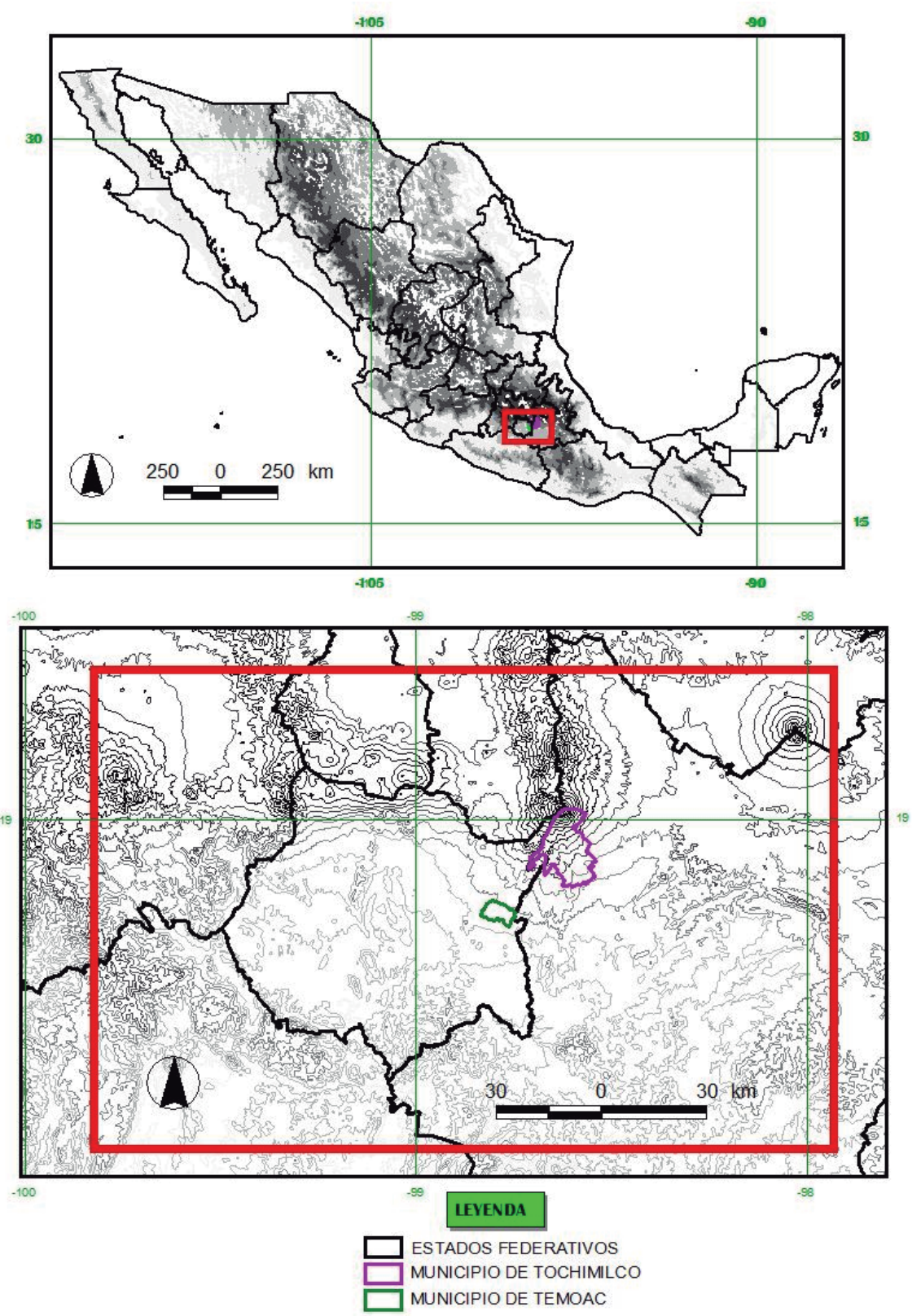

Figura 1 - Ubicación de la región de estudio.

Fuente: Elaboración propia a partir de datos de CONABIO (2015) e INEGI (2015) 


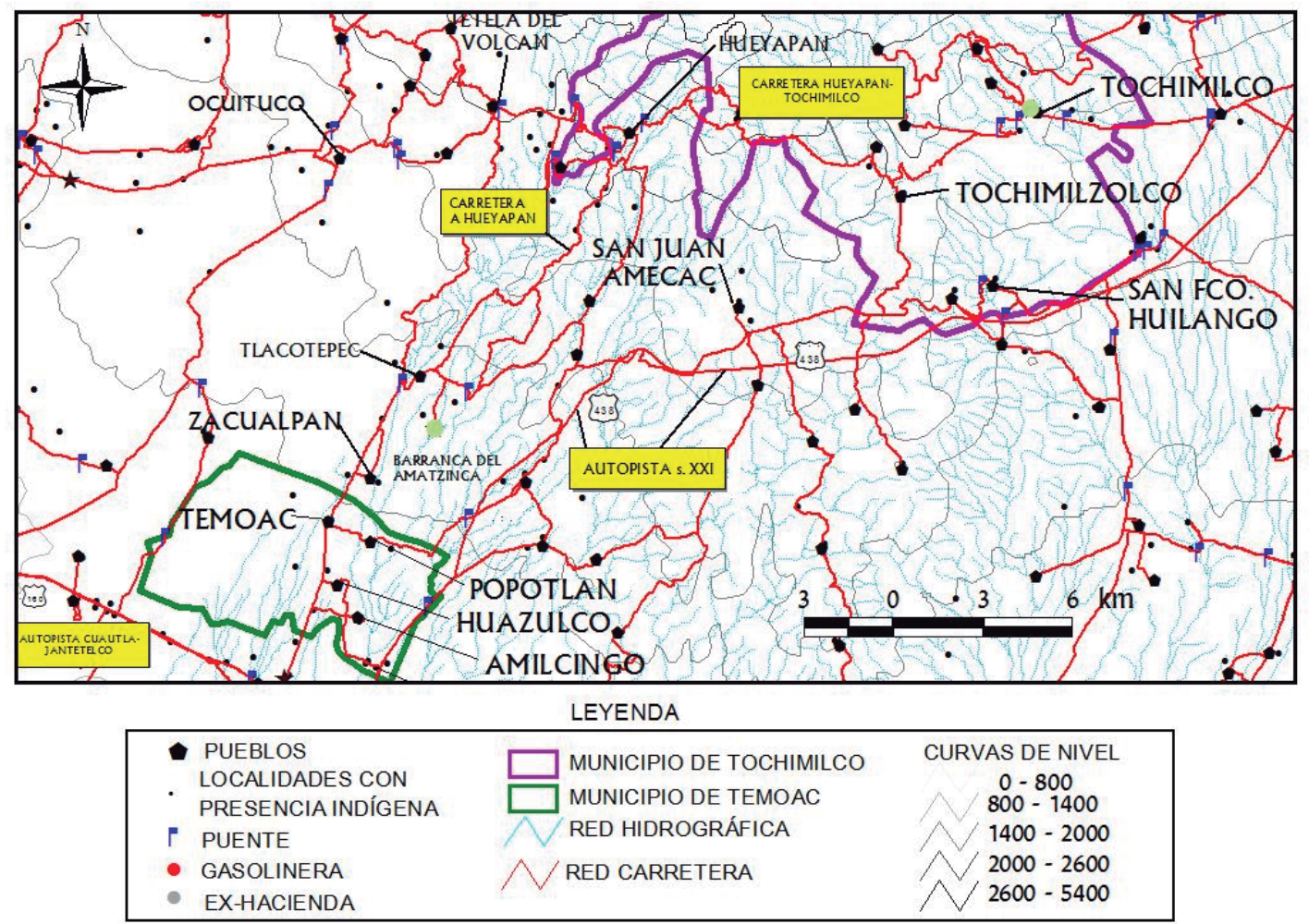

Figura 2 - Región de estudio, se delimitan carreteras y autopista s. XXI, pueblos, presencia indígena, puentes, gasolineras, ex Hacienda.

Fuente: Elaboración propia a partir de datos de INEGI, 2015; CONABIO, 2015.

\section{Los pueblos campesinos de la región: marginación y autonomía.}

El capitalismo, históricamente, ocupa la fuerza laboral de los campesinos para la agroindustria agrícola y el trabajo urbano, en paralelo al proceso de expropiación de tierras y desplazando mercados, imponiendo modos de vida y de producir para mantener el control de la producción de los alimentos, tinturas, hule, biocombustibles y fibras que se obtienen del campo.

Sobre los mecanismos de subsunción del capital al pequeño agricultor, junto al tener o no tener tierra y la renta de ella, está el sistema de compra, imposición de paquetes e infraestructura y la circulación de estas mercancías agrícolas. La pauperización constante y la convivencia de formas de generación de ganancias desiguales impiden satisfacer las necesidades básicas y sostener el gasto familiar (Oliveira, 2007; 1982). Los mecanismos postrevolución industrial mantenía el sistema de tienda de raya y extremos como el esclavismo, existen evidencias de estas prácticas en las haciendas del oriente de Morelos hasta el inicio de la revolución mexicana.

Rosa Luxemburgo ([1916] 1967) colocó énfasis en la importancia del sistema colonial como explicativo de la expansión del capitalismo, así como la importancia de los sistemas no capitalistas que son sometidos y violentados por el capital, pues permanecen, en muchos casos, como sistemas no-capitalistas de las regiones fuera de la Europa occidental y Estados Unidos. Eso, tanto por la incapacidad del capital de organizar, controlar e imponer todas sus reglas a todas las poblaciones mundiales al mismo tiempo, y, sobretodo la resistencia de los pueblos.

El cambio climático, la destrucción de los suelos y la contaminación de las aguas son ejemplo de una crisis global del sistema político de origen occidental, que obviamente incluye a los sectores progresistas y socialdemócratas. Las epidemias y pandemias 
modernas son un triste ejemplo de este desastre, causado por la deforestación y el mal trato del ser humano a los animales silvestres y domesticados.

La referida autora polaco-alemana analizó agudamente, tanto la expansión del capitalismo agrario en los Estados Unidos, como resultado del cambio decurrente de los llamados farmers y colonos protestantes norteamericanos, cada vez más dependientes del comercio, químicos y los grandes subsidios, expandido con mayor fuerza en finales del siglo XIX. Pero, esta autora, también señaló el despojo indígena de las tierras ancestrales por este hombre blanco, empujando y violentando su existencia a las periferias de los centros de extracción y control agrícola.

La expansión de los grandes "señores agrícolas" y las grandes colonias religiosas ortodoxas, conocidos en ambos lados del atlántico, el comienzo comercial de los agroquímicos e insumos petroquímicos, acontecía aceleradamente en Estados Unidos y Europa desde finales del siglo XIX, antes del inicio de la revolución verde, pero que se consolida globalmente después de la primera guerra mundial, y sobretodo de la segunda, catapultando el modelo petroquímico-genético en el mundo entero como sinónimo de orden, desarrollo y progreso. Sus consecuencias se viven de forma dramática hoy en día, aunque amplios sectores políticos y civiles se niegan a verlo y aceptarlo por ideologías petrificadas e intereses económicos billonarios.

Los límites del capitalismo ya eran observados también por Luxemburgo, pues se establecen en el sentido de que en cuanto más remplaza la producción capitalista a las no capitalistas, más se estrecha su capacidad de máxima expansión dentro de los límites del mercado y sobre todo de la naturaleza. Como el geógrafo Carl Sauer (1956), ciertamente evolucionista, pero agudo observador de la herencia ancestral, consciente de que nuestro saber occidental se orienta hacia el uso de la tierra durante un corto número de años, siendo que no semeja a la sabiduría del campesino primitivo arraigado en sus tierras ancestrales.

Por si fuera poco, como ya apuntaba el investigador mexicano Efraín Hernández Xolocotzi $(1998,139)$, “la tecnología agrícola tradicional [campesina] seguirá existiendo como opción de sobrevivencia en el capitalismo a gran parte de la población rural y como chivo expiatorio de la degradación de nuestros recursos naturales [...] y nuestra incapacidad de autonomía de alimentos básicos".

En términos muy generales, en el oriente de Mórelos el latifundismo republicano liberal en las haciendas del oriente de Morelos, basado en el cultivo de la caña-deazúcar era ostentoso durante la segunda mitad siglo XIX. Excentricidades al estilo monárquico eran la regla, grandes apropiaciones del líquido y tierras, así como lo era también, la esclavitud, pues los documentos y mapas indígenas virreinales que (pauperizadamente) garantía la tierra y el agua, perdían valides con las reformas republicanas liberales de Benito Juárez y Lerdo de Tejada. (Meiners, 2018)

Hoy en día en el oriente de Morelos predomina otro monocultivo, el sorgo y el maíz forrajero de temporal. La fase neoliberal se escribe desde hace 35 años y ha dejado a los pueblos sin el líquido vital nuevamente. Pero, estos pueblos reconstruyeron viejas relaciones de compra-venta con las localidades poblanas en cuestión, para hacer frente a las problemáticas que impiden sustentar sus necesidades básicas.

Pero los campesinos e indígenas han sido señalados por los capitalistas y sectores occidentales liberales, como culpables de la degradación o no aprovechamiento comercial de los recursos naturales para el desarrollo del país, como alertó Hernández Xolocotzi $(1998 ; 1988)$. Pues recibe ayuda asistencial en programas de marginación y pobreza, y no así, el respeto al rescate agroecológico de suelos y aguas, autonomía económica e innovación, imponiendo el modelo de desarrollo de la agroindustria por sobre sus territorios. 
Los campesinos de esta región presentan estrategias en búsqueda de autonomía ante el escenario hegemónico de perdedor-ganador (sum-zero game), por ejemplo, en torno al tema hídrico en los pueblos de Morelos. La tierra permanece como salvaguardia y como garantía de la reproducción social y territorial del campo y ante la expropiación del agua por el capital, que, apuesta por la erosión cultural de los pueblos, hasta imponer sus modos de vida y proyectos de supuesto progreso.

Sobre las respuestas de los actores a situaciones específicas, o implementación de proyectos y organización, con mayor problematización, Elinor Ostrom ([1990] 2015,1) estudió cómo los recursos comunes manejados por comunidades, no son pocos los casos que suelen desarrollar sofisticados mecanismos de decisión y aplicación de reglas para los conflictos de interés, como el propio sistema de riego. Siendo que, los actores, caracterizan las reglas que buscan resultados adecuados para cada situación particular. Y, estos sistemas se fragmentan, generalmente, por causas externas, como proyectos de infraestructura del capital, fenómenos del cambio climático y la explotación mineral.

$\mathrm{Al}$ respecto de la perdida de sistemas de aguas en los pueblos de Temoac, finamente organizados, ahora los pueblos de Hueyapan y Tetela del Volcán, al extremo norte de la barranca, retienen el líquido por sistemas de bombeo y un entramado de mangueras en las parcelas anexas, esto, principalmente, fomentado por el entonces gobernador (1982-1988) Lauro Ortega, que desató, como dueño de tierras y sistemas productivos, nuevos conflictos entre los pueblos que disputan el agua.

Pero, de una forma muy general, podemos decir que los resultados de Ostrom contrapusieron el paradigma imperante en economía, los estudios ambientales y las ciencias sociales, que fueron inspirados en la obra "Tragedia de los comunes" de Hardin (1968) y otros autores, quienes proponían que sucedería la degradación inevitable del ambiente cuando muchos individuos usan un recurso en común, en un modelo lineal y determinista. En otras palabras, "nadie puede parar la avalancha del progreso", que no puede alcanzarse, por ningún motivo, de forma autónoma.

El supuesto atraso económico y tecnológico de los campesinos en las periferias del capital, fue y continúa siendo en amplios sectores académicos, una postura sustentada en la línea de explicación estructural progresistas y afines al liberalismo económico, todo esto, sin analizar el colonialismo o las dinámicas internas de los actores en su teoría y complejidad. Lo que explica, según Ángel Palerm ([1980] 2008, 265), el “viejo entusiasmo por los programas llamados de modernización campesina". Como ejemplo claro, se tiene la labor de extensionistas y agrónomos, fuertemente dependientes de insumos químicos y respaldo financiero, lo que contrasta con el financiamiento al campesino, basado en el asistencialismo clientelar a fondo perdido y créditos.

La autonomía campesina e indígena, expresada en el grado de territorialidad a nivel comunidad, no así una ilusión de la realidad, "pura o romántica", como suele referirse, despectivamente, en sectores de las ciencias económicas y sociológicas, cuando se trata, por ejemplo, sobre los estudios relacionados al medio ambiente, etnobotánica, agroecología, o inclusive sobre las posiciones teóricas afines a ellas. Pero, en realidad, la territorialidad existente se ha basado en la sangre de muchas mujeres y hombres campesinos y eso no es romántico es violento.

El campo es un escenario complejo, donde se mezclan modos de vida específicos, subjetividades, costumbres, la modernización, el derecho a la educación, la tenencia o no de la tierra, el manejo diferencial de los recursos y el trabajo en el campo y las ciudades. La migración internacional resulta importante también en cambios y resignificaciones de hábitos de estas poblaciones, pero principalmente, en la entrada de ingresos económicos más significativos para las familias. 
El campesino tiene como bases fundamentales de organización a la familia y a la comunidad, y se da al interior de la dinámica de las regiones, en convivencia con múltiples procesos organizativos, vinculados al funcionamiento republicano, desde las ayudantías y cabeceras municipales y las autoridades ejidales, en la búsqueda de aplicación de justicia, ley, salud y educación. Las instituciones agropecuarias y relativas a los programas nutricionales, tales como las meriendas escolares, mismo que importantes, han privilegiado las alas modernizadoras como tendencia mundial, dejando a la agroecología como paliativa cuando se trata de la agricultura pequeña.

La producción agrícola aparece como dependiente de una tecnología enfocada en el manejo inteligente del suelo, el agua y la diversidad, por medio de trabajo humano y tracción animal, con poco capital, pero suficiente tierra y energía fósil disponible. Ciertamente, el modelo de producción agrícola moderno ha dejado suelos desgastados, daños por uso intensivo de agro-tóxicos y las afectaciones por las consecuencias del Cambio Climático Global. La pequeña agricultura ha sido afectada en ese proceso, tanto por adherirse a sus técnicas, como las consecuencias derivadas de otros productores en el mismo territorio.

Sin embargo, hoy en día, como ayer, los actores rurales han representado una fuerza de contención crucial, como alternativa a la expansión del capitalismo y la fase neoextractivista de los recursos, de un sistema patriarcal en el contexto del cambio climático, y, todavía, fuente de alimentos para las regiones urbanas.

No es por acaso que las y los líderes y miembros de organizaciones ambientalistas campesinas e indígenas, sean asesinados cada semana en Latinoamérica al defender sus territorios y su herencia. Los territorios indígenas y campesinos en México, Colombia, Brasil y otros países del Sur global, están amenazados y sus derechos fundamentales continuamente violentados. Samir Flores Soberanes (Figura 3) se une a este triste párrafo, como otro ejemplo de esta violencia por sobre las comunidades campesinas originarias, como ya aconteció décadas atrás a su tío y profesor rural Vinh Flores Laureano.

\section{De la parcela al taller}

Todos los campesinos aprendieron el oficio de dulceros por sus padres y abuelos, sólo uno de los entrevistados $(D)$ aprendió con $\tilde{N}, Q$ y $V$. Don $A x$ (1935-2014) relata lo que le enseñaron sus abuelos, y como él mismo enseño a sus nietos, no solamente en la fabricación de los dulces, sino de la siembra y los beneficios de la planta: nunca dejes de sembrar tu alegría, el alegría puedes tenerla tres, cuatro años, y no se te pica, el maíz se pica[se plaga], cualquier semilla otra se pica, [...] namás sécalo bien, cuando vez que está a buen precio, cuando lo cosechas está barato, guárdalo, cuando ya está más o menos algo carito, sácalo y vende. Pero tienes, pero si no tienes nada ¿qué cosa vas a sacar? (Figura 4 y 5 )

La mayor parte de la gente que se dedica a las actividades del campo en Temoac, Morelos, y lo hace en labores combinadas al cultivo de amaranto y su procesamiento, como el cacahuate, maíz, pero principalmente el sorgo y la fabricación de los dulces. En los pueblos que hacen parte del municipio de Tochimilco destaca como productos principales la siembra del amaranto, el maíz y en los últimos años se ha regresado la siembra de la chía.

Como se ha hecho hincapié, el cultivo del amaranto, el maíz, los frutales el frijol y el café, en el municipio de Temoac, ha dejado espacio a otros monocultivos como el sorgo. Pero, los propios procesadores que han parado de cultivar tienen memoria sobre su siembra familiar. El mismo $J R$ afirma: "hace años sembraba mi abuelo, después yo dejé de sembrar, y dejamos solamente a elaborar, a transformar" el huauhtli. 


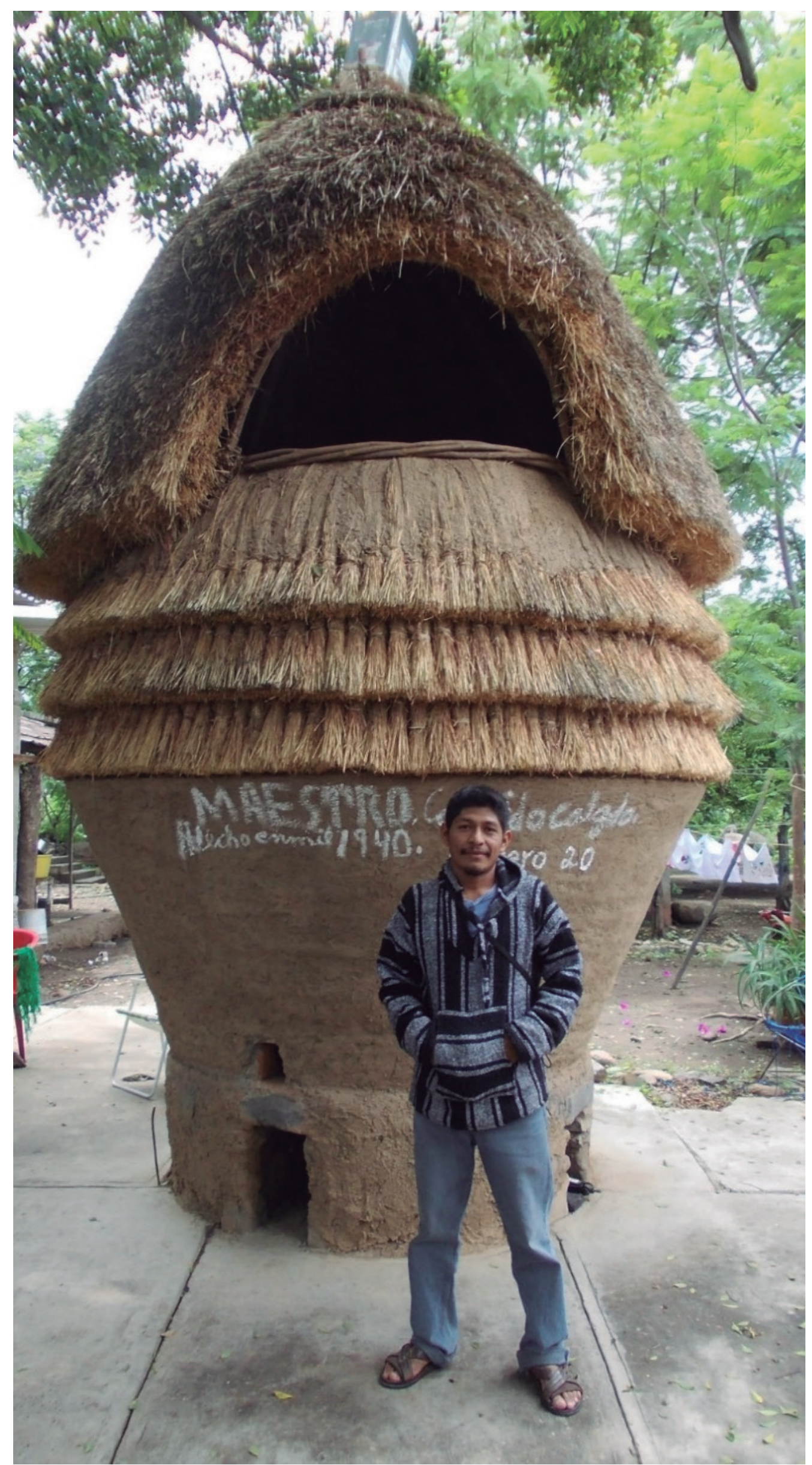

Figura 3 - Samir Flores (1985-2019) y el Cuexcomate (granero tradicional) en Amilcingo, Morelos. Fuente: Tomada por el autor. 


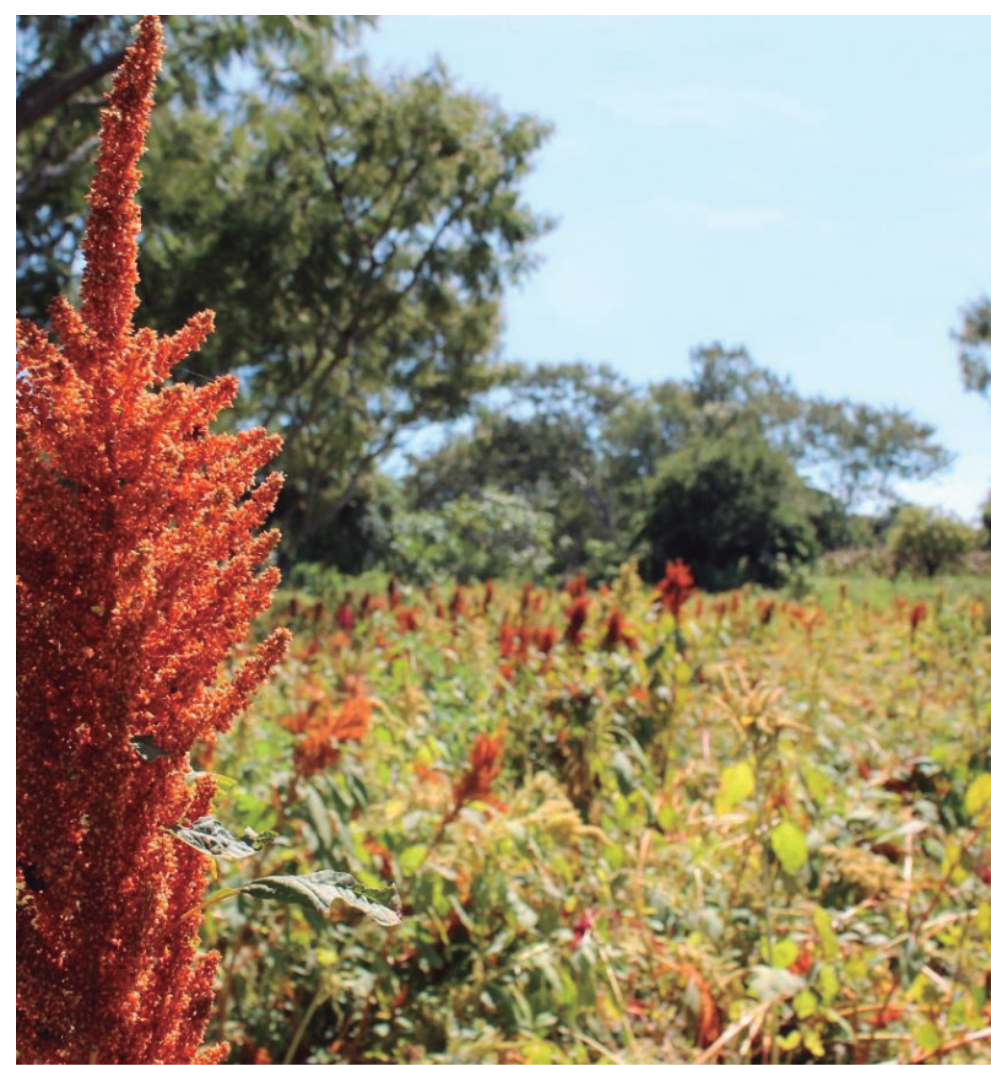

Figura 4 - Variedad Criollo Amilcingo (Amaranthus cruentus, raza mexicana) en el ejido de Amilcingo.

Fuente: Tomada por el autor (2014).

Una sucesión secular de monocultivos que explica la erosión agrícola, lingüística y cultural, pero con una férrea resiliencia indígena y campesina que manifiesta la permanencia del huauhtli en la microrregión y otros productos importantes, como el cacahuate y el café.

Los cultivos promovidos por el Estado, históricamente han privilegiado la explotación campesina, desde el trigo, la caña de azúcar y ahora el sorgo, a través del uso intensivo de la tierra, el agua, agroquímicos y maquinaria, que acompañan las dificultades climáticas. Esto no sólo existe por opción desesperada del campesinado para ser incluidos en el mercado capitalista de granos, sino por políticas estatales que así lo prefieren y que caminan en el objetivo del "desarrollo y la modernidad" insolente, desplazado los sistemas de regadío, milpa, huertos y solares tradicionales y otras opciones de desarrollo en los pueblos rurales.

$D$, resume la situación de la región en torno a los tipos de cultivos, así como la importancia de estas plantas en las comunidades, lo que explica también cómo es que las organizaciones no fueron "para adelante", y contrasta con el nicho familiarcomunitaria, el cual permitió seguir trabajando, en la comunidad sobre el tema del huauhtli:

En Huazulco la comunidad ha logrado preservar el amaranto, porque además de cultivarlo lo trabaja, y es una actividad que se tiene durante todo el año, si tú vas a los talleres, todos los talleres salvo algunos que, vamos a decir, pues la mayoría trabajan todo el año, ya haciendo alegría, palanquetas, hoy hay varias empresas que se dedican al cereal de manera muy exclusiva, pero es durante todo el año. A esto yo le atribuyo un poco la permanencia, el hecho de que se haya podido conservar y que esto genera para la comunidad fuentes de empleo y también ingresos adicionales a las familias, durante todo el año y no sólo del campo, como es el caso de Popotlán o Temoac, que básicamente subsisten de los cultivos de temporal, u otras actividades. Y, no sólo el amaranto, sino el cacahuate también. 
Las fiestas han sido, y continúan, una fuente importante de ingresos, $S$ relata la producción de su fábrica para el día de muertos: "estamos trabajando en eso, 1800 cajas de calaveras de amaranto cada año en la temporada, unos dos meses trabajando, a 19 pesos la calavera, en la Merced a 40 o 50 pesos". (Figura 5)

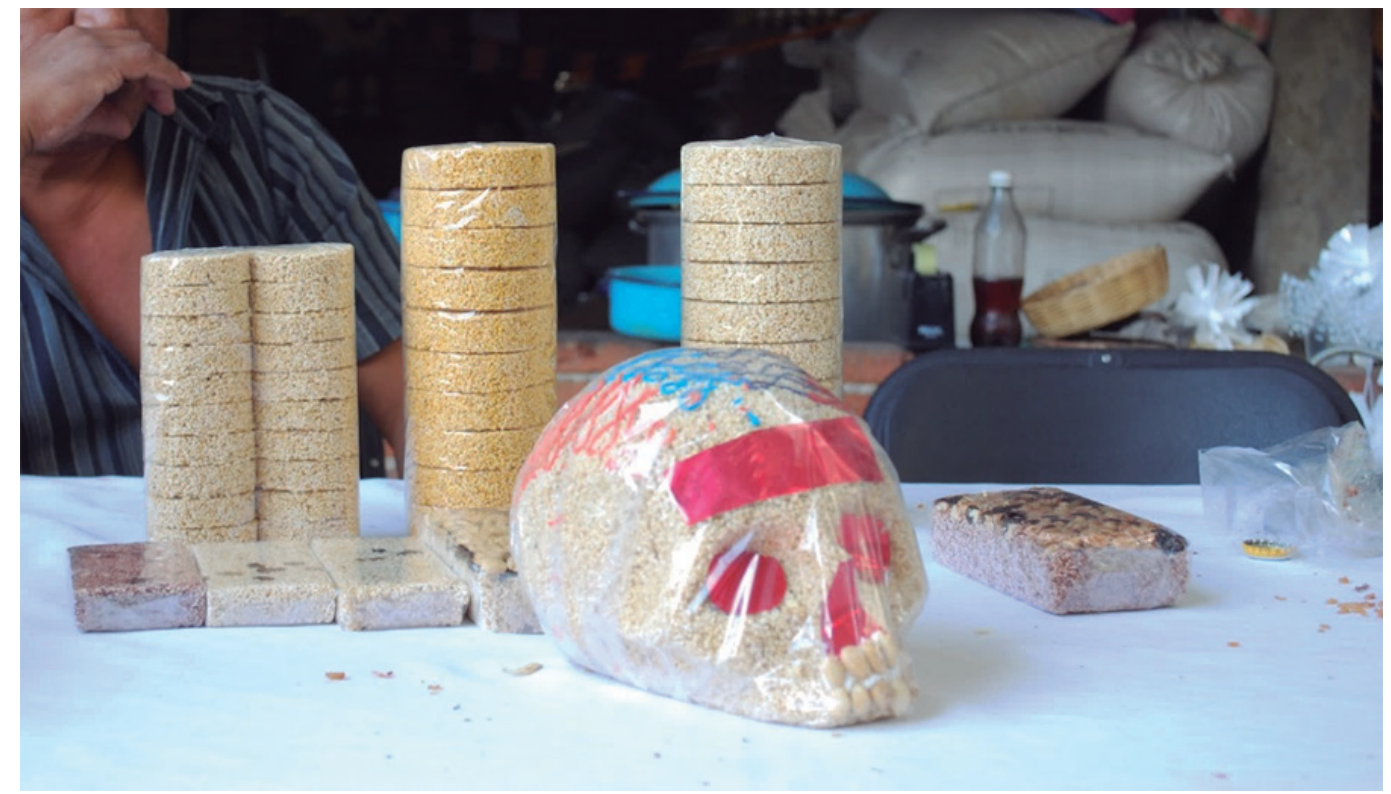

Figura 5 - Alegrías y calavera de amaranto en localidad de Huazulco, Morelos, en la foto $S$ con sus alegrías y calaveritas de amaranto.

Fuente: Tomada por el autor (2009).

$V$ también cuestiona que la actividad de salir a vender ya no es tanto como antes:

"se hacen productos de diferentes maneras, pero el dulce de amaranto es el principal, se hacen granolas, obleas, obleas con chocolate, etc. Pero en las tiendas y en las dulcerías vienen a comprar, ya no es de salir tanto, pues aprovechamos las casas. Y sigue siendo una actividad que se ha extendido a otros pueblos. Amilcingo está haciendo lo propio con pan, galletas, granolas, obleas [...]. El municipio se ha contagiado [...]. Cada quien va buscando como su propio cliente, como cuando compran lo que produzco, el amaranto con el chocolate en la comunidad, la gente lo consume y regresan, nos buscan, aunque no tengamos dulcería, yo soy dulcero artesanal, mis dulces son artesanales, no pongo químico a los productos".

Y esto, porque existen decenas de familias que se dedican a esa actividad y el tamaño de los talleres y los emprendimientos es variable. Incluso el crecimiento de los talleres con ingredientes naturales encuentra un excelente mercado y la búsqueda por productos con estas características es cada vez mayor.

La búsqueda de su propio cliente a través de sus propias relaciones comunitarias es lo más común, así como el centro procurado, ya sea el mercado de La Merced y su sección de dulces llamada "Ampudia" en la calle de Circunvalación, desde hace más de un siglo, o el mercado de "La bola" en la Ciudad de México o en los propios de Guadalajara, así también, en centros turísticos como Tepoztlán, Morelos, los dulceros reparten en sus carros y camionetas, se trasladan en autobuses o venden dentro de la comunidad, a los compradores al mayoreo que aparecen en las propias tiendasfábricas de los pueblos.

La tradición de venta en las ferias religiosas es igual de importante, como la Semana Santa, la feria de Santa Catarina Huazulco y el día de Muertos, donde los talleres más pequeños concentran sus ganancias. También se presenta la compra de productos 
por familias de migrantes que acuden en las festividades y vacaciones a los dichos pueblos para llevarlos para Estados Unidos.

\section{Talleres y organizaciones, entre la tradición y lo "moderno"}

En la comunidad de Huazulco, en el caso de las actividades económicas y culturales, existe cierto recelo, esencialmente entre algunas familias que defienden la elaboración tradicional de los dulces que contienen amaranto, ya que la gran mayoría del dulce fabricados actualmente en la comunidad carece de la miel de abeja y/o piloncillo o aguamiel, siendo que, anteriormente, esas eran las únicas materias primas usadas para endulzar y aglutinar los productos. Ahora esos productos vienen siendo desplazados por azúcar, glucosa y ácido cítrico en los últimos años. Como relata C: "Desde chavo su familia se dedicó a eso, la necesidad de buscar chamba, el autoempleo, buscando trabajo, entregábamos a la Merced. Pero considero que es de mala calidad la mayoría del producto de la Merced. Nosotros regresamos a elaborar el dulce, pero de buena calidad con miel y piloncillo. En realidad, en la comunidad más del 80\% elaboran dulce del común, con azúcar, glucosa y ácido cítrico. El resto lo elaboramos con miel".

En este sentido, la justificación de los talleres familiares (en sus distintas escalas) de fabricar los dulces con insumos de origen industrial, está relacionada a la problemática en torno a los precios, pues en palabras de $S$ : "Cuando es con miel es más cara, pero no nos conviene porque que el mercado hay mucha competencia de productos más baratos".

Dentro del poblado de Huazulco, las relaciones que los campesinos mantienen son complejas, mismo después de la separación de alguna organización, como el grupo productivo y cultural TX30, formado en los primeros años de la década de 1990, y ya separado hace quince años. Incluso después de conflictos internos, como el que motivó la separación de TX30, las familias campesinas que la conformaban tienden a mantener las relaciones comunitarias, por más complejas y contradictorias que sean, se reconfiguran, se negocian, se reconcilian, como relata $X:$ " $V$ le hace el trabajo del chocolate a $Q$, que es el distribuidor. Ellos van al pueblo de Tochimilco a comprar, pero cuando hay mucha producción depende de la demanda, porque cuando hay mucho no lo compran. $S$ es productor y $V$ es transformador. $D$ es el enlace, los grupos de cultura, vamos, nos salimos por cada uno a su rollo". Es importante que tanto E y $\tilde{N}$ han trabajado en el taller con $Q$, pues les da un sueldo en la fábrica y son hermanos. Y uno de los distintivos de la fábrica $H 2$ es la calidad de la alegría (uso de miel, piloncillo, cacao) además de la variedad de productos.

Estas personas, antes grupos y organizaciones, re-contruyeron su relación bajo la compra e intercambio de productos para su venta. Como es el caso de TX30, donde participaban: $C, \tilde{N}, Q, V, D, X$ y $E$, en conjunto con los integrantes de sus respectivas familias. El nuevo Sistema Producto del estado de Morelos, es ejemplo de nuevos acomodos de personas ya vinculadas en procesos organizativos, como la participación de $D$ y $V$ en los últimos tres años.

Sobre los motivos que llevaron al rompimiento de TX30, destacan las coincidencias sobre las exigencias que $\tilde{N}$ comenzó a establecer después de aparecer los problemas administrativos, por medio de criterios más estrictos al respecto de las finanzas y la organización laboral. Ya sobre las cuestiones personales, el propio $D$ considera que en cuestiones económicas ha sido difícil, "sólo por medio de pequeñas ventas, en tratar de sostener. La experiencia fue muy difícil, intento seguir trabajando con $C$, con $Q$ y con el hijo de $E$ (W06), con $V$, con $S^{\prime \prime}$. De hecho, $D$ es el único miembro que mantiene las actividades que se originaron con el nombre del extinto grupo, pero ahora de forma individual, y ha conseguido ser parte del consejo del Sistema Producto del amaranto junto con $V$, quien la dirige desde hace tres años. 
La empresa de $Q$ y $C$, cooperan para las ferias del pueblo con cierta relación con grupos de jóvenes, como el grupo Huazulco Renace, que está mucho más vinculado con los programas estatales de gobierno a nivel municipal, en de búsqueda de difusión del amaranto en el sector turístico y administrativo, como la realización de una feria anual que lleva cinco ediciones, realizada generalmente en los primeros días de noviembre.

Así, en estas comunidades resaltan tres tipos de relaciones. La primera, basada en las dinámicas internas entre los propios campesinos y talleres de los productos de amaranto. La segunda, se refiere a nivel regional y estatal, con los pueblos Tochimilco, Puebla (y ahora también Tlaxcala en los últimos cuatro años), que cultivan el amaranto y abastecen de la semilla a los fabricantes. Y la última, la venta de los dulces en ciertos nichos de mercado, los cuales, generalmente no son los mismos para evitar competencia directa en la comunidad.

Es común entre la gente del pueblo de Huazulco, la cuestión que en el pueblo "una mentalidad del agandalle, del poder, esto prevalece y en grupos pequeños", como apunta $C$. Es un proceso complejo, pues existe una realidad de carencia, de dificultades económicas, de violencia, de inconformidad y de desaliento. Para $C$, en Huazulco existe también "una competencia desleal" y una mala organización en sentido autocrítico.

Por otro lado, el empresario familiar $A C$, registra 40 empleos directos y la relación de compra y reventado de semilla de alrededor de cincuenta familias de Huazulco y Amilcingo, pues algunas familias surten también parte de sus productos, principalmente cajas de obleas y utilizan la reventadora (a precios accesibles) para reventar o "tostar la alegría", que los talleres mayores tienen instaladas en los talleres.

En el caso de $A C$, son siete hermanos, además del taller son dueños de una pequeña imprenta para elaborar la propia etiqueta de sus productos. Para este productor de dulce, en la gente prevalece el egoísmo y la apatía "Aquí, las gentes son muy egoístas, es un pueblo chico, era para que estuviera más organizado, pero no, cada quien jala agua para su molino. Existe la competencia de quien es el más fuerte [...] es una imitación negativa".

Como se ha dicho, es notable en algunos de los pobladores de la comunidad de Huazulco esas opiniones, incluso sobre un cierto descuido del pueblo y los solares cada vez más erosionados. Sin embargo, aparecen otro tipo de relaciones comunitarias que permanecen y que son base de la lógica y funcionamiento de los pueblos.

En relación a la pérdida de la producción de los dulces con la miel de abeja y piloncillo, ha traído problemas no sólo en la calidad nutricional de los productos, sino también en riesgo de tener que pagar impuestos especiales, sobre todo de los talleres mayores, como "productos chatarra". Lo anterior, por rebasar los límites de kilocalorías por gramos en los productos confeccionados. Según AC los talleres mayores "han venido a pagar ese impuesto especial de producción y servicios (IEPS) a través del Registro Federal de Contribuyentes, como ley publicada en el 2013. De estos tipos de producto se paga con tasas del 3\% al 8\%. Una salida a este problema sería el uso del aguamiel no fermentado de agave pulquero dado que está exento de pago, pero llegar a esas alternativas requiere de mucha organización y voluntad de cambiar el paradigma productivo y el problema de los precios.

Una vez más la responsabilidad recae en el propio pequeño productor que, en la mayoría de los casos, vive en condiciones de bajos recursos económicos. Aclarando, por fin, que la ley puesta en operación desde el año 2014, era necesaria, pero está mal direccionada, siendo que el objetivo central era la disminución del consumo de productos chatarra industriales ampliamente circulados en el país, como los refrescos, 
que cuentan con gran cantidad de azúcar y poseen mejores condiciones de resistir a estos cambios, mismo siendo afectados sus lucros.

En la realidad, dicha contribución sí ha dado más recursos al erario y sus vínculos empresariales, pero no ha disminuido los índices de obesidad de la población. La nueva ley de etiquetados de alimentos parece promisoria ante la necesidad de comunicar la correcta información nutricional, se verá en los próximos meses su aplicación y funcionamiento en condiciones pandémicas.

Dentro de las comunidades se encuentran muy buenos productos, como los elaborados por las pequeñas fábricas que venden con sus propias marcas, tales como: T3, H2, G1, etc. y otras familias con talleres aún mayores, como $C, A C, \tilde{N}, J R$. La experiencia de algunos de los campesinos-promotores, como $V, D, \tilde{N}, X, C$, así como la creciente diversificación de productos del taller de $Q$, son muestra de la capacidad campesina de mantener sus proyectos en funcionamiento.

Indiscutiblemente, sería adecuado en pensar en el fomento de la actividad, o vincularse a cadenas cortas de valor, tanto en el área apícola, como en el fomento al aprovechamiento orgánico de aguamieles de agave, el cacao, azúcar y piloncillo, y su obvio uso en los dulces, para mejorar el producto y generalizar prácticas sustentables en el medio rural campesino, hasta ahora aplicados en muy pocos casos.

\section{Viejos vínculos y actividades, nuevas relaciones y organizaciones}

La vocación dulcera y manufactura a base de amaranto, es un elemento nuclear de su cultura, que se convirtió en uno de los principales medios para la obtención de otros productos de uso diario en las familias. Y en el caso de Puebla, el cultivo y venta de las semillas, con tierras fértiles y disponibilidad de agua. En el año 2017, Tochimilco, Puebla cultivó 1120 ha, poco más de la mitad de la producción del estado de Puebla, y un tercio de la producción nacional de amaranto (3190 ha) (SIAP, Acceso 7 julio de 2018).

Entre las comunidades de Huazulco y Amilcingo se calculan alrededor de 200 familias relacionadas directa o indirectamente con el amaranto, dependiendo como se separen las relaciones familiares y los talleres, vinculadas a la actividad del amaranto, incluso en algunos talleres que les llaman localmente de "medianos o grandes". (Imagen 2)

Gran parte de los talleres (de 1 a 7 personas) ${ }^{4}$ o pequeñas fábricas y/o tiendas (más de 7 personas) están ubicadas en sus domicilios readecuados a sus necesidades, pero usando también los patios, solares y espacios de anexos de la casa. La venta se realiza tanto al mayoreo en cajas y con marcas propias registradas. Los comercializadores de otras ciudades no faltan, ya que compran los productos a precios atractivos en las localidades y colocan sus propias marcas registradas paras ser distribuidos, incluso en grandes cadenas comerciales como Aurrera ${ }^{\circledR}$, Comercial Mexicana ${ }^{\circledR}$ o Walmart ${ }^{\circledR}$ en el caso de las pequeñas fábricas.

Por otro lado, Temoac, que acostumbra regularmente sembrar rangos entre 100 y 450 ha anuales, en el año 2017 únicamente sembró 5 ha, como uno de los peores años en términos agrícolas desde los años ochenta. Además de la ya citada pérdida del agua de riego, esto se debe al aumento de producción de la semilla, al entrar de lleno en la producción el estado de Tlaxcala, lo que ha causado la disminución del precio de la venta de la semilla. (SIAP, Acceso, julio 2018). Puesto que, de pagar entre 5 mil pesos mexicanos en 2014 (150 kg), a 1500 pesos mexicanos (208 a 78 dólares americanos aproximadamente) en 2016, lo que desalentó la siembra en Morelos el 2017. Para los talleres esta situación no es tan perjudicial porque pueden comprar a mejor precio y

4 Se delimitó ese criterio para diferenciar el tamaño y cantidad de producción, pero en ambos casos poseen un componente familiar y comunitario nuclear en la organización. 
almacenar para producir más dulces, pero no parece adecuado pensando en términos de patrimonio y pérdida de semillas criollas.

Aún, cuando es obvio el problema de erosión genética al dejar de sembrar, no significa que los campesinos no guarden y/o intercambien sus semillas de amaranto una vez que resuelven sembrar de nuevo, o que no cultiven una pequeña superficie para preservarla sus variedades.

Se puede observar la diversidad de características y estrategias campesinas en Huazulco y Amilcingo, Temoac, Morelos, pero también en las comunidades de Tochimilco, San Francisco Huilango y San Juan Amecac en Puebla, como son: las actividades artesanales, ceramistas, culinarias y arquitectónicas. Es por esta razón que los llamados oficios, escuelas técnicas y costumbres adquiridas por muchos años en las familias son muy comunes.

Reventar las semillas de amaranto (kiwicha-pop) se ha hecho una actividad muy importante desde que las máquinas aparecieron en Huazulco, implantándolas en sus talleres. El uso del cacahuate, venderlo y cultivarlo en la región también es una actividad destacada en estos pueblos como el caso de Ty, puesto que está integrado al uso del amaranto, como la alegría con pasas y cacahuate, o el muy tradicional jamonsillo (dulce a base de cacahuate) fabricado en Huazulco y Amilcingo, como $Q$ y $A b$. Principalmente los hombres de la comunidad trabajan en los servicios que trajeron la urbanización, como taxis y en los últimos años las "bici-taxis" y "mototaxis", tortillerías mecanizadas, tiendas de abarrotes.

Así, C es un campesino que emigró a Estados Unidos en 1980, y trabaja desde hace más de cinco años en su taller de dulces, combinado con el trabajo en un taxi al regreso de aquel país, pues como relata $X:$ " $C$ regresó a producir la alegría en su taller, él es muy bueno y lo elabora con miel". Incorporando la actividad y buscando mantener la calidad de sus productos. Y como el propio $C$ comparte "dejé 14 años lo del amaranto. Regresé ahora, hace dos años, era taxista [...] y regresé a hacer los dulces [...] Desde chavo [niño], mi familia se dedicó a eso, la necesidad de buscar chamba [trabajo], el autoempleo, buscando trabajo, entregábamos a la Merced [Importante mercado en la Ciudad de México]".

$\tilde{N}$, por su parte, combina estadías fuera de la comunidad para atender pedidos y venta de amaranto de forma autónoma, así como el trabajo en la fábrica con sus hermanos $E$ y $Q$, elaborando y empaquetando los dulces desde hace más de treinta años (15 años en forma de pequeña-fábrica).

$X$ se vincula al trabajo de una ONG que tiene actuación en la región y relaciones con organizaciones estadounidenses y nacionales de trabajo comunitario, produce café de alta calidad gourmet y cultiva amaranto sin agroquímicos. Durante dos años montó una dulcería de amaranto en una ciudad próxima, pero tuvo que cerrarla por dificultades económicas.

Samir Flores Soberanes, nativo de Amilcingo, participaba de forma activa en la radio comunitaria por internet y una pequeña antena, llamado Radio Amilzinko100.7fm, uno de los principales opositores de los megaproyectos gubernamentales. El cultivaba su parcela de amaranto con su familia de forma orgánica y vendía su semilla sólo a los transformadores de Huazulco. Dentro de las actividades relacionadas con la radio, está la reforestación con árboles nativos y frutales en zonas contiguas a la barranca, la educación ambiental, la salud y la música. Además de tener el oficio de herrero para complementar sus ingresos.

El joven $R$ combina el trabajo como transportador de la mercancía diariamente en la fábrica familiar de amaranto con el cultivo esporádico de sorgo. $W$ cultiva sus parcelas con maíz, amaranto y cuida celosamente los cafetos de su solar, y nunca ha cultivado 
sorgo. $S$ ha trabajado la mayor parte de su vida en la fábrica familiar de dulces, perdió la costumbre de cultivar la tierra y aumentó significativamente la actividad dulcera como uno de los más activos talleres de Huazulco.

$V$ se compromete con el trabajo de difusión y promoción del amaranto y se vincula a los grupos de investigadores y productores del llamado Grupo de Enlace del Amaranto ${ }^{5}$, y hoy dirige el Comité del Sistema Producto del Amaranto en Morelos, además de continuar elaborando sus alegrías de chocolate y cultivar su milpa de traspatio. $Q$ ha crecido en la producción e infraestructura de la fábrica de dulces, convirtiéndose en uno de los mayores productores y vendedores del pueblo, sólo comparado a $S, A C$ y sus hermanos $\tilde{N}$ y $E$, también $J R, C$, que son conocidos por sus mayores volúmenes de venta.

Las campesinas $L, N$ y $A$ de Tochimilco, combinan sus actividades laborales como trabajadoras domésticas, cocineras o empresas o servicios en zonas urbanas. Algunas de ellas regresan a la comunidad por problemas de salud, como el caso de $A$, o migran temporalmente a EUA como $M$. Afortunadamente, algunas más continúan sus estudios, como hija de Don A que estudian en dos universidades públicas de la capital.

Ya en Huazulco y Amilcingo, las hijas y las esposas de las familias, como $C, Q, V$, $A C$, etc. trabajan en el campo y en la venta y empaque de los productos de amaranto y las obleas, estudian en nivel técnicos y también profesionales, participan en las labores del campo y trabajo en servicios en ciudades mayores cercanas, como Cuautla o Tepoztlán, Morelos. Las actividades de los talleres les han permitido ingresos suficientes para acceso a escuelas públicas en algunos casos, como los hijos de $\tilde{N}, A c$ y $Q$, o los sobrinos de $X$.

Se ha reportado más de dos mil empaquetamientos de productos por día de trabajo por cada una de las jóvenes de Huazulco (en su mayoría entre los 14 y 50 años aproximadamente). Las más jóvenes de la comunidad de Amilcingo y Huazulco suelen trabajar en los talleres familiares, el trabajo en servicios y comercio, así como estudiantes en la Escuela Normal Rural de Amilcingo, y otras opciones educativas y oficios de la región. La migración es mucho más significativa en el estado de Puebla, la mayoría a varios estados de Estados Unidos de América y como jornaleros y trabajadores en California, y nacional en Sonora y Baja California a la pisca de la uva.

La manufactura de dulces es poco conocida en las comunidades poblanas, siendo común la preparación de atoles y reventar para consumo familiar, pero la principal actividad es agrícola, complementando sus ingresos con las actividades económicas fruto de la migración.

En el caso de San Francisco Huilango, Puebla, se observa una vocación eminentemente campesina, como $A b$, que combina las actividades del campo (amaranto, maíz, trigo y frijol principalmente), con las actividades artesanales de piñatas y el trabajo temporal en las ciudades como plomero y vendedor. El amaranto se consolidó nuevamente en la cadena hace aproximadamente 35 años, precisamente cuando el riego también se esfumó de las comunidades de sur de la barranca en la etapa neoliberal. Las mujeres campesinas también cuidan de los solares y el trabajo del hogar en diversidad de tareas, ya sea de la comunidad o de pueblos vecinos con familiares como $A b$ de San Francisco Huilango, Tochimilco.

Don $R$ de Huilango, regresó al campo desde el 2003, después de una larga estadía en Acapulco, Guerrero, cuando trabajaba para un refresquera. Hoy Don R cultiva el amaranto en sus parcelas en rotación con el frijol, el trigo y el maíz.

5 Compuesto por productores, universidades y algunas ONG's. Esta organización promueve la inclusión del amaranto como producto estratégico para el país, pero su propuesta ha tenido más eco en los gobiernos de la Ciudad de México y algunos diputados de nivel estatal y federal. 
El trabajo como peones o jornaleros es común, sobretodo en pequeñas y media propiedades, además del trabajo familiar autónomo de sus propias tierras o de su familiar, tanto hombres como mujeres. Los peones reciben pagamientos diarios que van de los 100 a los 200 pesos mexicanos (5 a 10 dólares americanos) aproximadamente.

Para el caso del cultivo del huauhtli, se necesitan cinco o más personas por hectárea para ciertas tareas en el ciclo agrícola, como el deshierbe o la cosecha, actividades que sólo pueden ser suplidas cuando la familia no es suficiente, mediante la ayuda comunitaria o contratar personas que soporten en tales tareas, como el arado, abonado y barbechado.

Las parcelas campesinas, tanto en Morelos como en Puebla, poseen entre media hectárea y dos hectáreas por familia, aproximadamente. Por veces son mayores las extensiones de los cultivos cuando se renta o se trabaja en mediería con otros campesinos como lo hace $A c$ y Don $R$, que significa la colaboración en partes iguales de trabajo e ingresos en una misma parcela o utilización conjunta de maquinaria como tractores e insumos agrícolas. Los campesinos de Puebla tienen un mercado seguro pero injusto en los precios, esto último por la variabilidad y la incapacidad de apoyos en un sector olvidado por el Estado.

La llamada resiliencia agroclimática del amaranto se basa en su resistencia al stress hídrico, buen desarrollo en tierras salinas y pobres y no se plaga fácilmente cuando se almacena, a diferencia del frijol y el maíz, conocidos por su fácil proliferación de insectos y otros patógenos. Esas características permiten venta en mejores momentos coyunturales relacionado al precio de la semilla. De lo contrario, cuando es necesario, y no es posible esperar al precio subir, venden su producto en el momento que el comprador llega al pueblo para abastecer el mercado de los dulces en Morelos y otros estados.

Hasta ahora, esta dinámica contradictoria y compleja se ha mantenido por accionar de las mismas comunidades. Una posible injerencia de grupos promotores $\mathrm{u}$ organizaciones que representa la postura de una mayor participación del Estado en producción, negocio, tecnología, semillas, en una supuesta soberanía alimentaria, pero bajo el enfoque de alimento estratégico con precio estable, difícilmente despegados de visiones productivistas y biotecnológicas como la solución a todos los problemas del campo. Lejos de problematizar los complejos territorios comunitarios construidos, en gran parte autónomamente, $\mathrm{y}$, apuntala grandes desafíos, sobre todo en el contexto de crisis climáticas y económicas y un nuevo gobierno en contexto de pandemia.

\section{Consideraciones finales}

Esta planta es comprendida como patrimonio histórico alimentario en localidades campesinas de los pueblos. Mismo en condiciones desastrosas y violentas, los pueblos de esta región protegen las variedades de huauhtli, a través de su uso histórico, con base en su religiosidad, conocimientos agrícolas, relaciones comunitarias, organizaciones productivas, lucha social y en su economía campesina, materializado en la permanencia de cultivos milenarios como el huauhtli. Ese proceso, ha permitido asentar las bases del uso continuo de viejos costumbres, ahora, en su mayor parte como pequeños negocios familiares.

Huazulco y Amilcingo son los principales productores de mercancías a base de amaranto en México, solo comparado con los amaranteros de Tulyehualco, Xochimilco, Ciudad de México Los productores campesinos de Tochimilco y Atzitzihuacán, Puebla en conjunto con resurgimiento en Tlaxcala los últimos cinco años, son los mayores productores nacionales de estas semillas. 
El proyecto campesino y manufacturero planea su persistencia con un alto perfil comunitario, a pesar de la permanencia de distintas contradicciones y procesos de erosión lingüística, cultural y agrícola, separación de organizaciones, aunado a un escenario institucional y económico desigual. Sin embargo, es evidente entre las familias la búsqueda por nichos y clientes propios entre cada taller familiar y la reconfiguración de las organizaciones en nuevas relaciones a nivel familiar y comunitario, incluso de compra-venta de insumos y productos de amaranto.

Las actividades laborales de los campesinos son diversas, por ejemplo, la combinación del trabajo agrícola y otras actividades técnicas, educacionales, profesionales, saberes, oficios tradicionales y artesanales. La búsqueda por mejores ingresos económicos motiva la migración internacional como jornaleros o trabajadores urbanos en los Estados Unidos y norte de México, principalmente los campesinos del Estado de Puebla.

Al respecto de la venta de las semillas por las localidades del estado de Puebla, se observa que sólo las necesidades más vitales de los campesinos, los motiva a vender sus maquilas $(150 \mathrm{~kg})$ de amaranto con precio desfavorable. El precio de las maquilas de amaranto (fuera del control del campesino), claramente influye en sus estrategias locales y comunitarias cada año, así como las dinámicas de oferta, demanda y capacidad de asegurar sus cargas esperando mejor precio.

Las técnicas de cultivo tradicionales se mantienen, pero de manera mezclada con las técnicas agronómicas más modernas, primordialmente en el caso de Morelos, como son, el uso de las semillas híbridas y mejoradas y fertilizantes químicos.

Dentro de esos problemas la pérdida del agua destaca, como un problema enorme para los antiguos pueblos de regadío, que eran acostumbrados a un sistema comunitario bien organizado entre los pueblos de la barranca, como lo muestra la cartografía y esquemas de repartición de las aguas entre los pueblos.

En las poblaciones del estado de Puebla, preferencialmente los adultos, migran a Estados Unidos a trabajar legal o ilegalmente, y es una fuente importante de ingresos para las familias campesinas que permanecen en México.

Las relaciones de poder intracomunitarias constituyen opciones de supervivencia en torno a productos como estos. Las relaciones extracomunitarias no fueron benevolentes, y no lo son ahora, por lo que las disputas por el agua, la tierra y el modo de vida acontecen continuamente, y de forma violenta durante todo el trayecto histórico de la región.

La violencia se manifiesta por sobre los modos de vida, pero las comunidades reinventan sus resistencias, como lo ha sido la especialización del pueblo en la manufactura de las semillas del huauhtli. La desaparición física, tanto de Samir Flores, como la de su tío Vinh Flores Laureano, fueron duros golpes al sistema autónomo y comunitario de los pueblos de la barranca. Pero, como suelen referir en los pueblos de Temoac: ¡Samir es semilla, Samir se siembra!

El huauhtli consiguió resistir el desprecio colonial, el olvido republicano y la ignorancia de la modernidad, principalmente, basada en la lucha revolucionaria de los pueblos zapatistas y su necia persistencia campesina-indígena, guste o no, con una relación distinta con la naturaleza.

Los nuevos programas del gobierno, que colocan al huauhtli en la canasta básica, por más que necesarios, no incluyen en su operación las propuestas y experiencias, como las colocadas en cuestión, no respetan la autonomía, y sí, por el contrario, confirman la implementación de megaproyectos heredados de administraciones pasadas, lo que afectan la organización, ambiente, modo de vida y cultura de las poblaciones. 
La marginación y olvido del huauhtli no debe ser sustituida por la difusión monolítica y productivista de los alimentos, tendrá que ser reconocida como opción autónoma de formas y usos de comunidades enteras.

Finalmente, se reflexiona, que hoy en día, existe un resurgimiento de usos alimenticios y comerciales de súper-alimentos como el huauhtli o la quinua, pero en su mayoría en esquemas fetichizados gourmet, lo que excluye a la población general, encarece los productos y no favorece a la mayoría de los campesinos, pues no existe una política sólida para el pago justo a los productores en cadenas de comercios justos, o la aparición en meriendas escolares, restaurantes universitarios públicos, hospitales, asilos, orfanatos o incentivos comerciales para su producción y consumo general en mercados orgánicos y campesinos.

\section{Bibliografía}

Chayanov, Alexander. ([1916] 1974). La organización de la unidad económica campesina. Buenos Aires, Argentina: Nueva Visión.

Cruz, Sor Juana Inés de la. (1994). Sor Juana Inés de la Cruz. Obra selecta. Tomo I. Caracas, Venezuela: Biblioteca Ayacucho.

De la Serna, Jacinto. ([1657]1892). Manual de ministros de indios. Para el conocimiento de sus idolatrías, y extirpación de ellas. Ciudad de México, México: Imprenta del Museo Nacional.

Fanon, Franz. (1961). Los condenados de la tierra. México D. F., México: Fondo de Cultura Económica.

Hardin, Garrett. (1968). The tragedy of the commons. Science, 162(3859),1243-1248. doi: 10.1126/ science.162.3859.1243

Hernández Xolocotzi, Efraín. (1998). Metodología para el estudio de agroecosistemas con persistencia de tecnología agrícola tradicional. En M. A. Díaz León, y A. Cruz León. (Eds.), Nueve mil años de agricultura en México. Homenaje a Efraín Hernández Xolocotzi. (pp. 110-124). México D. F., México: Ed. Grupo de estudios ambientales.

Hernández Xolocotzi, Efraín. (1988). La agricultura tradicional en México. Comercio Exterior, 38(8), 673-678.

Luxemburgo, Rosa. ([1916] 1967). La acumulación del capital. México D. F., México: Grijalbo.

MacNeish, Richard. (1964). Ancient Mesoamerican civilization. Science, 143 (3606), 531- 537. doi: $10.1126 /$ science.143.3606.531

Oliveira, Ariovaldo Umbelino de. (2007). Modo capitalista de produção, agricultura e reforma agrária. São Paulo, Brasil: FFLCH/LABUR.

Oliveira, Ariovaldo Umbelino de. (1982). A pequena produção agrícola mercantil no Brasil. Boletim Goiano de Geografia, 2(2),165-195.

Ostrom, Elinor. ([1990] 2015). Governing the commons. The evolution of institutions for collective action. Cambridge, United Kingdom: Cambridge University Press.

Palerm, Ángel. ([1980] 2008). Antropología y marxismo. México D. F., México: UAM, Universidad Iberoamericana.

Porto-Gonçalves, Carlos Walter, y Leff, Enrique. (2015). A ecologia política na América Latina: a reapropriação da natureza, a reinvenção dos territórios e a construção da racionalidade ambiental. Desenvolvimento e Meio Ambiente, 35, 65-88. doi: 10.5380/dma.v35i0.43543

Revillagigedo, Don Juan Vicente de Güémez Pacheco de Padilla Horcasitas y Aguayo. (1790). Compendio Bandos de la Ciudad de México. Periodo colonial. 1790-03-23. Recuperado de https://www.bandosmexico.inah.gob.mx/todos/1790_03_23.html

Revillagigedo, Don Juan Vicente de Güémez Pacheco de Padilla Horcasitas y Aguayo. (1791). Compendio Bandos de la Ciudad de México. Periodo colonial. 1791-04-16. Recuperado de https://www.bandosmexico.inah.gob.mx/todos/1791_04_16.html 
Sahagún, Bernardino de. (1577). Historial general de las cosas de la Nueva España. México. Libro decimo de los vicios y virtudes desta gente indiana y de los miembros de todo el cuerpo interiores y esteriores y de las enfermedades y medicinas contrarias y de las nationes que a esta tierra an venido a poblar. Recuperado de https://www.wdl.org/

Sahagún, Bernardino de. (1577). Historial general de las cosas de la Nueva España. México. Libro undecimo que es Bosque, jardin, vergel de lengua Mexicana. Recuperado de https:// www.wdl.org/

Sahagún, Bernardino de. (1577). Historial general de las cosas de la Nueva España. México. El dozeno libro: tracta de como los españoles conquistaron a la ciudad de Mexico. Recuperado de https://www.wdl.org/

Sauer, Carl. (1956). The Agency of Man on the Earth. En T. Jr. William L. (Ed.), Man's Role in Changing the Face of the Earth (pp. 49-69). Chicago, United States: University of Chicago Press.

Sistema de Infomación Agrícola y Pecuaria. Avance de siembra y cosechas. Resumen nacional por cultivo. (2018). Recuperado de http://infosiap.siap.gob.mx:8080/ agricola_siap_ gobmx/AvanceNacionalSinPrograma.do

Universidad Nacional Autónoma de México. (2012). Gran Diccionario Náhuatl [versión electrónica], CDMX, México: UNAM, http://www.gdn.unam.mx 